\title{
Improving Team Collaboration in Patient Transfer Processes by Co-Workers' Perceptions and Suggestions
}

DOI: 10.12776/QIP.V25I2.1559

Lilly-Mari Sten, Pernilla Ingelsson, Ingela Bäckström, Marie Häggström

Received: 2021-04-01 Accepted: 2021-07-12 Published: 2021-07-31

\begin{abstract}
Purpose: The purpose was twofold: first to describe how co-workers within a team perceived team collaboration in patient transfers from an intensive care unit (ICU) to general wards and, second, to describe co-workers' suggestions for an improved future state of team collaboration.

Methodology/Approach: Focus group discussions (FGDs) were conducted at two medium-sized hospitals located in Sweden. Participants were multidisciplinary and from both ICUs and general wards. Data were analysed using qualitative deductive content analysis.

Findings: An expressed need for improving team collaboration was a defined and well-designed ICU transitional care process with a holistic view of how to create quality of care, and a standardised process for continuous improvements. This should involve co-workers from different professions and hospital units, as well as patients and relatives. Other views raised by the co-workers were clearer definitions of roles, responsibilities and deeper insights on how team members depend on each other's work efforts to succeed.
\end{abstract}

Research Limitation/Implication: This study was conducted at two hospitals, hence no generalizable conclusions can be made.

Originality/Value of paper: Co-workers collaborating in a ICU transitional care process can have important insights in how to improve team collaboration. This can be of great importance in increasing quality of care where multiprofessional teams from different organisational cultures are collaborating.

Category: Research paper

Keywords: ICU transitional care; patient transfer process; quality improvement; quality of care; team collaboration 


\section{INTRODUCTION}

Health care organisations face multiple challenges when providing safe care with quality, while at the same time reducing waiting times and increasing efficiency (Fine et al., 2009). Applying Quality Management (QM) can be one way to address these challenges. An important part of QM is working in teams, both within and across organisational boundaries. Collaborating in teams across organisational boundaries can create a learning organisation (Ljungberg and Larsson, 2018). Team collaboration can also contribute to maximising performances of individuals with good teamwork and even duplicating effort, and interdependent work tasks can be performed more efficient (Murphy and Heberling, 1996).

The quality of team collaboration has a direct impact on the quality of an organisation's outcomes and performance (Boughzala and de Vreede, 2015), and effective teamwork has been shown to be crucial for providing optimal patient care when handling critically ill (Reader and Cuthbertson, 2011). Coordination and delivery of safe, high-quality care demands reliable teamwork and collaboration within, as well as across, organisational, disciplinary, technical and cultural boundaries (Rosen et al., 2018). The transfer of patients from an intensive care unit (ICU) to general wards is an activity that is difficult to plan and perform due to the patient's health condition. This transfer process is called ICU transitional care (Chaboyer, James and Kendall, 2005). To provide safe care with quality within ICU transitional care, it is crucial to combine different unique skills and knowledge of co-workers in order to improve patient safety (Manser, 2009; Häggström and Bäckström, 2014), reduce medical errors, preventable deaths (Manser, 2009; Lyubovnikova et al., 2015) and cut health care costs (Vyt, 2008).

In summary, the way members of teams within ICU transitional care are collaborating in teams and how they improve team collaboration can be important in how to increase quality of care within ICU transitional care. The purpose of this study was therefore twofold: first to describe how co-workers within a team perceived team collaboration in patient transfers from an ICU to general wards and, second, to describe co-workers' suggestions for an improved future state of team collaboration.

\section{TEAM COLLABORATION}

According to previous research, there are some common characteristics for team collaboration, which have been discussed by several authors (i.e. Manser, 2009; Reader and Cuthbertson, 2011; West and Lyuvovnikova, 2012; 2013; Salas et al., 2015; Lyubovnikova et al., 2015). These charactersitics can be summarized as: Team structure and team members; Team tasks, roles and responsibilities; Team planning, reflexivity and continuous improvements; Team leadership and team decision-making; Team communication, competence and learning and Team organisational culture. 
A requirement of good teamwork is that teams are clear about who their members are (West and Lyubovnikova, 2012) and that members are aware of the importance of team composition (Salas et al., 2015). Teams also need to be clear about teams' tasks, roles and responsibilities. Task interdependence is the degree to which team members depend on one another for both individual and team task completion (West and Lyubovnikova, 2013). Richardson, West and Cuthbertson (2010) consider team reflexivity to be the extent to which team members collectively reflect on their shared objectives and processes, and adapt them according to current or expected conditions. Reflexivity is associated with continuous improvements. According to Manser (2009), leadership is an aspect of teamwork that is relevant to the quality and safety of patient care in dynamical domains of health care. Positive teamwork can be influenced by leadership and team dynamics (Walton et al., 2020). Ingelsson, Bäckström and Snyder (2018) conclude that managers having been able to work with teams and co-workers' perceptions of the whole organisation, enhanced involvement and ownership as a collective. Management can stimulate teams to become 'self-organisations' by enabling learning and knowledge sharing, promoting communication, and creating opportunities for collaboration and interactions between people (Poksinska and Swartling, 2018). Team communication is essential in team work (i.e. Manser, 2009; Richardson, West and Cuthbertson, 2010). This also involves competence and learning. Teams working on highly interdependent and complex tasks must constantly share information, discuss different perspectives, reflect on their performance and agree upon shared goals (Richardson, West and Cuthbertson, 2010). According to Salas et al. (2012), organisational culture is a critical consideration of team work and collaboration. Research shows that there seems to be a difference between the care cultures of ICUs and those of general wards, which can affect both the staff's cooperation and the perception of the transfer for patients and relatives (Häggström, Asplund and Kristiansen, 2009; Häggström and Bäckström, 2014). In ICU, teams continually alter due to large staff numbers, shift work and staff rotations. The ideal 'unified' team working together to provide better care and improve patient outcomes may therefore be difficult to sustain (Rose, 2011).

\section{METHODOLOGY}

\subsection{Project}

The research presented is conducted as part of a research project called 'Increased Quality and Efficiency in Patient Transfers'. The project group consists of researchers from two research subjcects: Quality Management and Nursing Science and was initiated in January 2018. The overall purpose of the project is to gain new knowledge about how quality and efficiency in patient transfers within ICU transitional care can be improved, focusing on leadership, continuity of care, safety culture and learning. 


\subsection{Settings}

This study involved two medium-sized hospitals located in Sweden. One hospital has 2,500 employees and approximately 400 beds, and the other hospital has about 3,000 employees and approximately 440 beds.

\subsection{Data Collection}

Multiprofessional focus group discussions (FGD) were conducted between November 2018 and January 2020. This data collection method was chosen as the researchers wanted to gain a broader and deeper understanding of team collaboration within ICU transitional care. Leaders at two ICUs and two general wards recruited participants working as physicians, ICU nurses, ward nurses, assistant nurses and physiotherapists. This can be seen as a convenience sampling, as the leaders and not the researchers chose the respondents. Totally 9 FGDs with 47 co-workers were conducted; $28(60 \%)$ of the participants were from ICUs and 19 (40\%) from general wards. Each FGD had 4-6 participants.

There were two researchers in each FGD, one acted as a moderator and one as an assistant moderator. The moderator guided the participants with open-ended questions from a semi-structed interview guide, used to ensure that all FGDs had the same basic lines of inquiry (cf. Patton, 2015). The guide embraced four overarching areas; quality of care, team collaboration, success factors and strengths and continuous improvements, developed from previous research. The FGDs lasted until all questions had been discussed and there was no new information from the participants. Upon the conclusion by each FGD, the moderator and the assistant moderator briefly reviewed the discussions. The duration of each FGD was 45-60 minutes, all were digitally recorded and transcribed verbatim.

\subsection{Content Analysis}

A qualitative deductive content analysis containing of three phases and inspired by Elo and Kyngäs (2008) was performed to further analyse the manifest content of the texts. During the first phase, the preparation phase, the unit of analysis was selected i.e a word or a theme (Polit and Beck, 2004). In this study the unit of analysis was described as: Team collaboration within and between hospital units. Transcriptions from the FGDs were read and listened to several times by the project members to gain a sense of the whole. In the second phase, the organising phase, a deductive structured analysis matrix was developed. Characteristics for teams and team collaboration constituted generic categories and a deductive analytical framework. These characteristics, were identified in QM and health care literature about team collaboration (described earlier in section 2 Team Collaboration). The matrix also included subheadings for each subcategory. These subheadings were 'Perceived current state' and 'Suggestions for improvements'. Data were coded in the matrix according to the generic categories and to perceived current state and suggestions for improvements 
(see Table 2), and in relation to the aim of the study. Aspects from the data that fit into the categories were sorted into the matrix. Data that did not reflect team collaboration were not sorted into the matrix and not analysed. This was followed by the last resulting phase, an interpretative process that included sorting similar codes together within each generic category and subheading. Subcategories were developed by notes and headings were written down using many headings in order to describe all the aspects of the content. Subcategories were given contentcharacteristic names that were all relevant for the generic categories, subheadings and the purpose. Table 1 shows an example of how the analysis was performed.

Table 1 - Example of the Content Analysis - Unit of Analysis, Generic Categories, Subheadings, Subcategories and Codes

\begin{tabular}{|l|l|l|l|}
\hline \multicolumn{1}{|c|}{ Unit of analysis } & \multicolumn{1}{|c|}{ Generic categories } & \multicolumn{1}{c|}{ Subcategories } & \multicolumn{1}{c|}{ Codes } \\
\hline $\begin{array}{l}\text { Team collaboration } \\
\text { within and between } \\
\text { hospital units }\end{array}$ & $\begin{array}{l}\text { Team structure and } \\
\text { team members }\end{array}$ & $\begin{array}{l}\text { Perceived current state } \\
\text { A lack of cross- } \\
\text { organisational teams }\end{array}$ & $\begin{array}{l}\text { 'Today there are no teams } \\
\text { that are working cross- } \\
\text { organisational'. }\end{array}$ \\
\hline $\begin{array}{l}\text { Team collaboration } \\
\text { within and between } \\
\text { hospital units }\end{array}$ & $\begin{array}{l}\text { Team tasks, roles and } \\
\text { responsibility }\end{array}$ & $\begin{array}{l}\text { Suggestions for } \\
\text { improvements } \\
\text { A new role for } \\
\text { analysing accidents } \\
\text { and risks }\end{array}$ & $\begin{array}{l}\text { 'A proposal for a new role as } \\
\text { an analysis manager, who } \\
\text { leads the work around } \\
\text { conducting analyses and } \\
\text { follow-ups of accidents and } \\
\text { risks in ICU transitional } \\
\text { care'. }\end{array}$ \\
\hline
\end{tabular}

\subsection{Ethical Considerations}

This study was conducted in full accordance with ethical principles and the project has been ethically evaluated by the Swedish Ethical Review Authority (Dnr. 2018-159-31M). Participants in the FGDs were given both written and oral information by the moderator, on the purpose of the study, that data would be handled confidentially and anonymously, and that the participants had the right to withdraw at any time. They were also informed that the participation was voluntary.

\section{RESULTS}

Results from the content analysis are described in accordance with the purpose of this study: how co-workers within a team perceived team collaboration in patient transfers from an ICU to general wards and how co-workers described suggestions for an improved future state of team collaboration. The structure of the unit of analysis, generic categories, subheadings and subcategories are presented in Table 2 . 
Table 2 - The Structure of the Unit of Analysis, Generic Categories, Subheadings and Subcategories

\begin{tabular}{|c|c|c|}
\hline \multicolumn{3}{|c|}{ Unit of Analysis: Team collaboration within and between hospital units } \\
\hline \multirow[t]{2}{*}{ Generic category } & \multicolumn{2}{|c|}{ Subcategories } \\
\hline & Perceived current state & Suggestions for improvements \\
\hline $\begin{array}{l}\text { Team structure and } \\
\text { team members }\end{array}$ & $\begin{array}{l}\text { - Construction of teams varies } \\
\text { - A lack of cross-organisational teams }\end{array}$ & $\begin{array}{l}\text { - Sharing resources between ICU and } \\
\text { general wards }\end{array}$ \\
\hline $\begin{array}{l}\text { Team tasks, roles } \\
\text { and responsibilities }\end{array}$ & $\begin{array}{l}\text { - Ambiguity about who are responsible } \\
\text { for what } \\
\text { - The same staff not at the same meetings } \\
\text { - Easier to collaborate if you know each } \\
\text { other }\end{array}$ & $\begin{array}{l}\text { - A new role for analysing accidents and } \\
\text { risks } \\
\text { - Physiotherapists should have a more } \\
\text { central role }\end{array}$ \\
\hline $\begin{array}{l}\text { Team planning, } \\
\text { reflexivity and } \\
\text { continuous } \\
\text { improvements }\end{array}$ & $\begin{array}{l}\text { - Working with improvements across } \\
\text { professional and functional boundaries } \\
\text { can be improved } \\
\text { - A forum for continuous improvements } \\
\text { can be developed } \\
\text { - No standardised process for continuous } \\
\text { improvements } \\
\text { - Following-up implemented } \\
\text { improvements can be better }\end{array}$ & $\begin{array}{l}\text { - Multi-professional and multidisciplinary } \\
\text { care conferences } \\
\text { - Reflection after patient transfers and } \\
\text { accidents } \\
\text { - Involve patients and relatives in } \\
\text { improving team collaboration } \\
\text { - A group working on continuous } \\
\text { improvements of team collaboration }\end{array}$ \\
\hline $\begin{array}{l}\text { Team leadership } \\
\text { and team decision } \\
\text { making }\end{array}$ & $\begin{array}{l}\text { - Ambiguous who decides and what } \\
\text { - Decisions are often made within } \\
\text { professions } \\
\text { - Parallel systems between professions } \\
\text { and hospital units }\end{array}$ & $\begin{array}{l}\text { Decisions on team improvements } \\
\text { applying to several hospital units are } \\
\text { being moved up to managerial level }\end{array}$ \\
\hline $\begin{array}{l}\text { Team } \\
\text { communication, } \\
\text { competence and } \\
\text { learning }\end{array}$ & $\begin{array}{l}\text { - Structure for reporting information is } \\
\text { not clear } \\
\text { - Reporting is not always multi- } \\
\text { professional } \\
\text { - Uncertain about whether information } \\
\text { reaches the right receiver } \\
\text { - Showing interest in visiting each other's } \\
\text { units } \\
\text { - Different competences at different } \\
\text { hospital units }\end{array}$ & $\begin{array}{l}\text { - A joint multidisciplinary report } \\
\text { - Involving assistant nurses more in } \\
\text { communication and information transfer } \\
\text { - Communicating in an easier way } \\
\text { - Creating a learning environment }\end{array}$ \\
\hline $\begin{array}{l}\text { Team } \\
\text { organisational } \\
\text { culture }\end{array}$ & $\begin{array}{l}\text { - Feeling safety and ease when helping } \\
\text { each other } \\
\text { - Different cultures at different hospital } \\
\text { units } \\
\text { - A lack of team collaboration between } \\
\text { ICU and ward } \\
\text { - The process for ICU transitional care is } \\
\text { undefined } \\
\text { - Different views of existing hierarchy in } \\
\text { the organisation and teams }\end{array}$ & $\begin{array}{l}\text { - Time for team collaboration } \\
\text { - Develop team collaboration } \\
\text { - No hierarchy in team collaboration }\end{array}$ \\
\hline
\end{tabular}




\subsection{Team Structure and Team Members}

\subsubsection{Perceived current state}

Co-workers collaborating in teams within ICU transitional care described that there were different organisational memberships in different teams and that the construction of teams varied. For example, had physiotherapists their organisational membership at another ward unit than the ward nurses and assistant nurses. Ward nurses and assistant nurses often collaborated within the hospital unit, and physicians joined at rounds and physiotherapists sometimes at reconciliations. The construction of the teams was also dependent on, whether the hospital context was an ICU or a ward unit. ICU teams were often multiprofessional, and the most common members in ICU teams were physicians, ICU nurses, assistant nurses, physiotherapists and other specialists.

Co-workers perceived there was a lack of cross-organisational teams collaborating along the whole ICU transitional care process. Sometimes teams would visit a ward after transferring a patient to that ward, but this was not in essence perceived as team collaboration.

\subsubsection{Suggestions for improvements}

In order to achieve more appropriate team collaboration and a process with higher quality of care, one suggestion for improvements of team collaboration was sharing resources between ICU and general wards. Sharing resources could make it possible for additional co-workers to help patients with, for example mobilisation or other care:

...before, there were those who were physiotherapists' assistants, or whatever it was called, who were around and helped.... maybe you could share that resource. One instructs how the other should work, together then with the hospital unit staff. In any case, there would be one more that could help in the mobilisation phase.

\subsection{Team Tasks, Roles and Responsibilities}

\subsubsection{Perceived current state}

Co-workers perceived there was ambiguity about who was responsible for what when handing over patients from ICU to general ward. Sometimes, ward staff would wait for the physiotherapist to make an assessment before they could start mobilisation.

Different professions attended different reconciliations and team rounds: the same staff were not at the same meetings. For example, physicians and nurses attended care conferences and physiotherapists and assistant nurses did not. Another example was, physicians attending rounds but not always reconciliations. 
Co-workers perceived it was easier to collaborate if they knew each other and each other's competences. Co-workers worked in three different shifts and as a result, co-workers collaborated with different people. Continuity in staffing was perceived as important by the co-workers.

\subsubsection{Suggestions for improvements}

Co-workers suggested a new role for analysing accidents and risks. An analysis manager could be responsible for conducting analyses and follow-ups of accidents and risks in ICU transitional care. This could be part of improving team collaboration between departments and thereby increasing the quality of care and patient safety.

Another suggestion was that physiotherapists should have a more central role and attend rounds and reconciliations. Sometimes the physiotherapist was viewed as being like a consultant and just attending on a few occasions.

\subsection{Team Planning, Reflexivity and Continuous Improvements}

\subsubsection{Perceived current state}

According to continuous improvements, co-workers perceived that working with improvements across professional and functional boundaries could be improved. Nurses and assistant nurses often worked together or separately on improvements, and physiotherapists often worked with other physiotherapists. When it came to improvements that did not only involve their own hospital unit, it became even more complex:

It is easier for us in the group to make changes. But there are many hospital units that have to be involved, if we are to do the same things everywhere. It is not easy to get that cooperation....

Suggestions for improvements from co-workers could be raised once a month at staff meetings. Those meetings were mostly attended by nurses and assistant nurses. Physiotherapists did not often attend staff meetings and did not have a forum for discussing continuous improvements. Co-workers believed that $a$ forum for continuous improvements could be developed including both within and between ICU and general wards.

It was not always clear how suggestions for improvements should be handled. Co-workers thought that there was no standardised process for continuous improvements and routines for how improvements could be notified, implemented and followed up.

Co-workers thought that the following-up of implemented improvements could be better. New routines were not always easy to keep to and make part of everyday work. In stressful situations it was easy to fall back into old habits. Often there was no follow-up at all and the changes did not last. 


\subsubsection{Suggestions for improvements}

Co-workers described that there was a need for multi-professional and multidisciplinary care conferences. Today, not all professions attended care conferences. If assistant nurses and physiotherapists also attended, this was seen by the co-workers to improve team collaboration and increase quality of care. There was a desire by the co-workers for a multidisciplinary gathering of the ICU and ward before patient transfers and to draw up care plans together, planning for a seamless process and continuity of throughout the whole process transferring the right patient to the right hospital unit at the right time:

High quality of care is when you... the right patient in the right hospital unit, then it will automatically be higher quality of care, I would say.

...time of course. What time of day too. But it has to do with planning.

One suggestion from the co-workers was to have a permanent item for patient transfers on the agenda for the rounds. This would provide an opportunity to discuss up-coming patient transfers multi-professionally.

In several of the FGDs co-workers perceived a need for reflection after patient transfers and accidents: objective analysis of a patient transfer or an accident, conducted together with all the parts involved and with a no-blame culture, raising what was good and where it went wrong.

It was also important to involve patients and relatives in team collaboration in order to improve team collaboration and thus quality of care and patient transfers. Co-workers assumed that if care teams knew the needs of patients and relatives before the patient transfer, for example according to information being transferred between care teams from different hospital units, it would increase the value of the transfer.

Co-workers saw a need for a group that worked on continuous improvements of team collaboration. This group should be multi-professional and cross organisational boundaries.

\subsection{Team Leadership and Team Decision-Making}

\subsubsection{Perceived current state}

Co-workers felt it was ambiguous who decided and what. Notes about patient transfers often included a name of a clinic, but not the name of who actually decided. For example, who decided the time for the patient transfer or the patient's medicine after the transfer:

Clarity, these things often fall between the cracks. You don't know who will really decide. Do we decide how long they should have antibiotics or is it another ward? Or they themselves? who is it?

Decisions were often made within professions, for example between assistant nurses or physicians. 
Co-workers thought there were parallel systems between professions and ICU and general wards and that they had little power to influence other professions or hospital units:

Yes, but we have rounds at the ICU, and there we have talked about... But then you make contact..., so it is like parallel systems that are not interconnected. I do not think it is so successful.

\subsubsection{Suggestions for improvements}

Co-workers suggested that decisions on team improvements that applied to several hospital units should be moved up to managerial level. Otherwise, there would be too many opinions and difficult to reach consensus. Management at a higher level has to decide and tell them 'this is where we want to go'.

\subsection{Team Communication, Competence and Learning}

\subsubsection{Perceived current state}

Handovers including information transfers between teams were made in different forum. Not all co-workers in the team received the same information and at the same times. The structure for reporting information was not perceived as clear and reporting was not always multi-professional, for example physiotherapists reported to each other.

Nurses and assistant nurses communicated with each other but not with physicians and physiotherapists. Assistant nurses did not report on rounds, even though they had much information about the patient: '...but we never report anything, although we might have had a lot to add'.

Co-workers felt uncertain about whether information reached the right receiver. Co-workers were unsure if information was passed on to the right co-workers at other hospital units. There were many new hired nurses with no previous experience of ICU transitional care and critically ill patients, and it could be difficult for them to understand the information, compared with more experienced co-workers:

They are so busy understanding what I am really saying, compared with how it was before, when many had worked for a long time and been in similar situations many times.

Co-workers from receiving and sending units described showing interest in visiting each other's units before and after patient transfer as positive. Coworkers from a receiving unit could then create a picture of the patient and his or her needs and the sending unit could follow up the patient's health conditions. In some of the FGDs, co-workers also talked about a lack of interest and that they did not feel engagement from the receiving part in getting to know the patient. On the other hand, they also felt that the ward staff were stressed and that the sending part tried to help by transferring the patient to the ward. 
There was a perceived gap between the ICU and the ward with regard to nurses' competence and understanding. Co-workers described that there were different competences at different hospital units. This was seen as a threat and a big obstacle to continuity of care, quality of care and patient safety. However, it was not just about competence, co-workers at ICUs also thought there was a lack of understanding of why it was important to do the things that the ICU staff did:

It's not really a lack of knowledge; I don't think so. It's pretty much basic stuff. But perhaps more of an awareness of why it is important. Otherwise it will just be something they have to do, that they find difficult.

\subsubsection{Suggestions for improvements}

Co-workers suggested that a joint multidisciplinary report, from the ward team and the ICU team, could prevent information from being lost.

They expressed a desire for assistant nurses to be more involved in communication and information transfer. Assistant nurses often have deep and personal information about the patients, which can be very valuable for them and their relatives, as well as for the co-workers within the process.

Co-workers, especially at the ICU, believed they could think more about how to communicate in an easier way and not use ICU terms all the time. This could facilitate understanding for co-workers at ward units.

In the FGDs, co-workers suggested that learning was created when analysing transfers and accidents and that this analysis should be conducted together with participants from both sending and receiving units. This would create a learning environment.

\subsection{Team Organisational Culture}

\subsubsection{Perceived current state}

The co-workers felt safety and ease when they helped each other, for example when physicians called a ward regarding patients' health conditions before a night shift. This routine made the co-worker on the ward feel safer. Co-workers also described that it was easy to stop someone in the corridor to ask for help.

Co-workers felt that there were different cultures at different hospital units. This sometimes led to misunderstandings. For example, there were different assumptions at hospital units on how information about test results should be provided. One co-worker described it as: 'These are preconceived notions that are then built into the culture'.

In the FGDs, co-workers described that there was a difference between ICUs and wards in the way they worked and described patients' health conditions. Ward staff sometimes thought that co-workers at the ICU had so much knowledge and that ward staff did not understand their information. They were sometimes afraid of asking co-workers from the ICU. 
Some co-workers thought there was a lack of team collaboration between ICU and ward. They sometimes had meetings, but they did not really see them as team collaboration. In contrast, other co-workers thought that team collaboration was good between hospital units and within their unit.

Co-workers felt that the process for ICU transitional care was undefined and not described in sufficient detail, as well as understaffed. Co-workers described all links as essential for the whole to work. Co-workers expressed a need for a more holistic perspective of the process from a customer perspective based on the needs of the patients and relatives and on the needs of the co-workers.

There were different views of existing hierarchy in the organisation and teams. Some co-workers did not perceive that there was a hierarchy at their unit, while others experienced a hierarchy as there being differences between the professions for those who were going to participate in, for example, care conferences and rounds:

I think we have a rather non-hierarchical approach at our clinic compared with some others. And that is probably what most of us mean by teamwork. I think, that is because we work with each other and are close to each other as well, I think.

\subsubsection{Suggestions for improvements}

Co-workers thought that time for team collaboration was a primary resource that was often missing. Staff were mostly stressed and did not have time for communication or visiting each other's units, receiving information and learning.

They believed there was a need to develop team collaboration, mostly between ICU and general wards and a suggestion from the wards was also to involve the ICU in improving team collaboration.

Co-workers thought it was important that there was no hierarchy in team collaboration. Co-workers believed that team collaboration prevented hierarchy and some people using power over others. All team members have different roles and tasks and the team need to collaborate interdependently in order to achieve high quality of care.

\section{ANALYSIS AND DISCUSSION}

The purpose for this study has been twofold: first to describe how co-workers within a team perceived team collaboration in patient transfers from an ICU to general wards and, second, to describe co-workers' suggestions for an improved future state of team collaboration.

From the analysis it can be seen that there was a perceived lack of crossorganisational teams working along the process, which also often made a gap and discontinuity in care. The importance of team collaboration between ICU and general wards is also discovered in previous health care research (i.e. Vyt, 2008; 
Häggström, Asplund and Kristiansen, 2009; Rosen et al., 2018) and seen as an important element within ICU transitional care and when reaching quality of care and patient safety (Häggström, Asplund and Kristiansen, 2009; Häggström and Bäckström, 2014). Similar conclusions were drawn in a previous study measuring team collaboration with a questionnaire (Sten et al., 2021). The results from the tested questionnaire indicated to some extent that teams collaborating over hospital units within ICU transitional care needed to focus more on how to increase person-centered care and continuous learning and how to create prerequisites for successful patient transfers between hospital units. Thus, working across organisational boundaries in multiprofessional teams can be associated with several challenges as ineffective communication, individual personalities, lack of understanding roles and responsibilities, and organisational structure (Walton et al., 2020). Also, time, uncoordinated treatment planning and leadership were seen as additional challenges connected to interdisciplinary team collaboration at ward rounds (ibid.).

A desire raised by the co-workers in how to improve quality of care, was to involve patients and relatives in improving team collaboration in patient transfers. This is similar with results from Häggström, Asplund and Kristiansen (2014) indicating that relatives wanted to be part in the transfer and also be prepared in advance for the change.

The analysis from this study described percieved 'parallel systems', which thought to be avoided involving and communicating decisions to the whole team and across organisational boundaries. Thus, there was an expressed need among the co-workers for a clearer decision process, both in daily work and when working on improvements. In a study by Poksinska and Swartling (2018), the authors concluded that to keep the improvement programme alive, there is a need for teams to take responsibility for managing and improving daily operations.

Co-workers described that there was variation in the structure of the care teams and some professions had their memberships at other hospital units than those they were working at. In a well-performing process and in efficient teams, tasks, roles and responsibilities need to be clear (i.e. Richardson, 2011; West and Lyubovnikova, 2012; 2013). In this study, co-workers in the process perceived, in a similar way as decision-making, that there was ambiguity about who did what. Due to large staff turnovers and three shifts, co-workers met new team members almost every day. That team members understand daily goals of care including the required tasks, care plans with clear responsibilities and plans for interdisciplinary communication seems like a groundwork of ICU management (Rose, 2011).

From the analysis it can be seen that handovers were not always multiprofessional and this could sometimes lead to deficiencies in information and uncertainty on whether the information really reached the receiver and the receiver understood. Co-workers also perceived a gap in competence and deficiencies in understanding why it was important to deal with different unit 
specific issues. Häggström, Asplund and Kristiansen (2009) stated in their study that one cause of the gap within ICU transitional care is differences in nurses' competences. Suggestions from the co-workers to help solve this problem were a multidisciplinary report with co-workers from both ICU and general ward, involving assistant nurses more and analysing patient transfers together, both ICU and general ward. Reflecting together was described by the co-workers as a way of creating a learning environment. Reflexivity and continuous improvements are important activities for 'real teams' (i.e. West, 2013; West and Lyubovnikova, 2013). Co-workers expressed a need for a standardised process for quality improvements. Having a structured and systematic way of handling suggestions for quality improvements and involving co-workers from different professions and hospital units, as well as patients and relatives, could help improve team collaboration and increase quality of care. When co-workers described their future state of team collaboration they proposed a special group including different professionals working across organisational bounderies with suggestions for quality improvements.

\section{CONCLUSIONS}

From the results of this study, some overarching conclusions can be drawn. Firstly, results indicated that an expressed need when improving team collaboration, is a defined and well-designed ICU transitional care process with a holistic view of how to create quality of care, continuity in care and a learning environment. Secondly, findings according to team collaboration, could be interpreted as a need for a standardised process for working with continuous improvements, mainly when it came to quality improvements that affected multiple hospital units, and that involved co-workers from different professions and hospital units, as well as patients and relatives. Also, a standardised and structured process for communication, competence exchange, decision-making and leadership for teams in ICU transitional care could be seen as important in order to improve team collaboration and to increase quality of care and patient safety. Thirdly, findings indicated a need for clearer definitions of team memberships, roles and responsibilities and deeper insights on how team members depend on each other's work efforts to succeed. Embedded in this is a need for a welcoming and positive organisational culture within and between teams.

Several of the conclusions from this study can be confirmed in previous research about teams and team collaboration, i.e. the importance of clear roles, responsibilities and structures for communication, competence exchange, planning and decision making. And also, the importance of teams working within and between ICU and general wards with continuous improvements and organisational culture. 


\section{RESEARCH LIMITATION AND FUTURE RESEARCH}

Future research could focus on implementing suggestions for improvements, evaluating these implementations, and measuring team collaboration and quality of care within ICU transitional care. This future research may also be applicable in other health care contexts as well.

More research is needed on how teams can collaborate more successfully across organisational boundaries and become teams that collaborate from a holistic perspective and with patient focus in a well-designed ICU transitional care process where patients and relatives are involved in the design.

\section{ACKNOWLEDGEMENTS}

The authors gratefully acknowledge the Kamprad Family Foundation for funding this research under grant number 20170084.

\section{REFERENCES}

Boughzala, I., and de Vreede, G.-J., 2015. Evaluating Team Collaboration Quality: The Development and Field Application of a Collaboration Maturity Model. Journal of Management Information Systems, [e-journal] 32(3), pp.129-157. DOI: 10.1080/07421222.2015.1095042.

Chaboyer, W., James, H. and Kendall, M., 2005. Transitional care after the intensive care unit: current trends and future directions. Critical Care Nurse, [e-journal] 25(3), pp.16-29.

Elo, S., and Kyngäs, H., 2008. The qualitative content analysis process. Journal of Advanced Nursing, [e-journal] 62(1), pp.107-115. DOI: 10.1111/j.13652648.2007.04569.x.

Fine, B.A., Golden, B., Hannam, R. and Morra, D., 2009. Leading Lean: A Canadian Healthcare Leader's Guide. Healthcare Quarterly (Toronto, Ont.), [e-journal] 12(3), pp.32-41. DOI: 10.12927/hcq.2013.20877.

Häggström, M. and Bäckström, B., 2014. Organizing Safe Transitions from Intensive Care. Nursing Research and Practice, [e-journal] 2014 (Article ID 175314), 11p. DOI: 10.1155/2014/175314.

Häggström, M., Asplund, K. and Kristiansen, L., 2009. Struggle with a gap between intensive care units and general wards. International Journal of Qualitative Studies on Health and Well-Being, [e-journal] 4(3), pp.181-192. DOI: 10.1080/17482620903072508.

Häggström, M., Asplund, K. and Kristiansen, L., 2014. Important quality aspects in the transfer process. International Journal of Health Care Quality Assurance, [e-journal] 27(2), pp.123-139. DOI: 10.1108/IJHCQA-09-2012-0090. 
Ingelsson, P, Bäckström I. and Snyder, K., 2018. Strengthening quality culture in private sector and health care: What can we learn from applying soft measures?. Leadership in Health Services, [e-journal] 31(3), pp.276-292. DOI: 10.1108/LHS-02-2018-0012.

Ljungberg, A. and Larsson, E., 2018. Processbaserad verksamhetsutveckling Varför - Vad - Hur? (in Swedish). Lund: Studentlitteratur AB.

Lyubovnikova, J., West, M.A., Dawson, J.F. and Carter, M.R., 2015. 24-Karat or fool's gold? Consequences of real team and co-acting group membership in healthcare organizations. European Journal of Work and Organizational Psychology, [e-journal] 24(6), pp.929-950. DOI: 10.1080/1359432X.2014.992421.

Manser, T., 2009. Teamwork and patient safety in dynamic domains of healthcare: a review of the literature. Acta Anaesthesiologica Scandinavica, [e-journal] 53(2), pp.143-151. DOI: 10.1111/j.1399-6576.2008.01717.x.

Murphy, D.J. and Heberling, M.E., 1996. A Framework for Purchasing and Integrated Product Teams. International Journal of Purchasing and Materials Management, [e-journal] 32(2), pp.11-19. DOI: 10.1111/j.1745-493X.1996.tb00281.x.

Patton, M.Q., 2015. Qualitative research and evaluation methods: integrating theory and practice. $4^{\text {th }}$ ed. Thousand Oaks, Calif.: SAGE Publications Inc.

Poksinska, B. and Swartling, D., 2018. From successful to sustainable Lean production - the case of a Lean Prize Award Winner. Total Quality Management \& Business Excellence, [e-journal] 29(9-10), pp.996-1011. DOI: 10.1080/14783363.2018.1486539.

Polit, D.F. and Beck, C.T., 2004. Nursing Research: Principles and Methods. $7^{\text {th }}$ ed. Philadelphia: Lippincott Williams \& Wilkins.

Reader, T.W. and Cuthbertson, B.H., 2011. Teamwork and team training in the ICU: Where do the similarities with aviation end?. Critical Care, [e-journal] 15(6), pp.313-313. DOI: 10.1186/cc10353.

Richardson, J., 2011. An investigation of the prevalence and measurement of teams in organisations: the development and validation of the real team scale. $\mathrm{PhD}$. Aston University. Available at: <http://ethos.bl.uk/OrderDetails.do?uin=uk.bl.ethos.551041> [Accessed 19 March 2021].

Richardson, J., West, M.A.. and Cuthbertson, B.H., 2010. Team working in intensive care: current evidence and future endeavors. Current Opinion in Critical Care, [e-journal] 16(6), pp.643-648. DOI: 10.1097/MCC.0b013e32833e9731. 
Rose, L., 2011. Interprofessional collaboration in the ICU: how to define?. Nursing in Critical Care, [e-journal] 16(1), pp.5-10. DOI: $10.1111 / \mathrm{j} .1478-5153.2010 .00398 . x$.

Rosen, M.A., Diaz Granados, D., Dietz, A.S., Benishek, L.E., Thompson, D., Pronovost, P.J. and Weaver, S.J., 2018. Teamwork in healthcare: Key discoveries enabling safer, high-quality care. American Psychologist, [e-journal] 73(4), pp.433-450. DOI: 10.1037/amp0000298.

Salas, E., Shuffler, M.L., Thayer, A.L., Bedwell, W.L. and Lazzara, E.H., 2015. Understanding and Improving Teamwork in Organizations: A Scientifically Based Practical Guide. Human Resource Management, [e-journal] 54(4), pp.599-622. DOI: 10.1002/hrm.21628.

Salas, E., Tannenbaum, S.I., Kraiger, K. and Smith-Jentsch, K.A., 2012. The Science of Training and Development in Organizations: What Matters in Practice. Psychological Science in the Public Interest, [e-journal] 13(2), pp.74-101. DOI: 10.1177/1529100612436661.

Sten, L.-M., Ingelsson, P., Bäckström, I. and Häggström, M., 2021. The development of a measurement instrument focusing on team collaboration in patient transfer processes. International Journal of Quality and Service Sciences, [e-journal] 13(1), pp.45-62. DOI: 10.1108/IJQSS-04-2020-0055.

Vyt, A., 2008. Interprofessional and transdisciplinary teamwork in health care. Diabetes/Metabolism Research and Reviews, [e-journal] 24(S1), pp.S106-S109. DOI: $10.1002 / \mathrm{dmrr} .835$.

Walton, V., Hogden, A., Long, J.C., Johnson, J. and Greenfield, D., 2020. Exploring interdisciplinary teamwork to support effective ward rounds. International Journal of Health Care Quality Assurance, [e-journal] 14(33,4-5), pp.373-387. DOI: 10.1108/IJHCQA-10-2019-0178.

West, M.A. and Lyubovnikova, J., 2012. Real Teams or Pseudo Teams? The Changing Landscape Needs a Better Map. Industrial and Organizational Psychology, [e-journal] 5(1), pp.25-28. DOI: 10.1111/j.1754-9434.2011.01397.x.

West, M.A. and Lyubovnikova, J., 2013. Illusions of team working in health care. Journal of Health Organization and Management, [e-journal] 27(1), pp.134-142. DOI: $10.1108 / 14777261311311843$.

West, M.A., 2013. Creating a culture of high-quality care in health services. Global Economics and Management Review, [e-journal] 18(2), pp.40-44. DOI: 10.1016/S2340-1540(13)70007-0. 


\section{ABOUT AUTHORS}

Lilly-Mari Sten ${ }^{0000-0003-1078-5676}$ (L.-M.S.) - Department of Quality Technology and Management, Mid Sweden University, Östersund, Sweden, Ph.D. Student in Quality Technology, e-mail: lilly-mari.sten@miun.se.

Pernilla Ingelsson $^{0000-0001-5610-2944}$ (P.I.) - Department of Quality Technology and Management, Mid Sweden University, Östersund, Sweden, Ass. Prof., e-mail: pernilla.ingelsson@miun.se.

Ingela Bäckström ${ }^{0000-0001-7621-2649}$ (I.B.) - Department of Quality Technology and Management, Mid Sweden University, Östersund, Sweden, Prof., e-mail: ingela.backstrom@miun.se.

Marie Häggström ${ }^{0000-0002-9936-8395}$ (M.H.) - Department of Nursing Sciences, Mid Sweden University, Sundsvall, Sweden, Assoc. Prof., e-mail: marie.haggstrom@miun.se.

\section{AUTHOR CONTRIBUTIONS}

Conceptualization, L.-M.S., P.I., I.B. and M.H; Methodology, L.-M.S., P.I., I.B. and M.H; Validation, L.-M.S., P.I., I.B. and M.H.; Formal analysis, L.-M.S., P.I., I.B. and M.H; Investigation, L.-M.S., P.I., I.B. and M.H; Writing - Original draft preparation, L.-M.S.; Review and editing, L.-M.S., P.I., I.B. and M.H; Visualization, L.-M.S.; Project administration, I.B.; Funding acquisition, I.B., P.I. and M.H.

\section{CONFLICTS OF INTEREST}

The authors declare no conflict of interest. The funders had no role in the design of the study; in the collection, analyses, or interpretation of data; in the writing of the manuscript, or in the decision to publish the results.

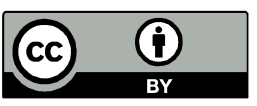

(C) 2021 by the authors. Submitted for possible open access publication under the terms and conditions of the Creative Commons Attribution (CC-BY) license (http://creativecommons.org/licenses/by/4.0/). 